\title{
Co-axial Fed Rectangular Microstrip Patch Antenna for 5.2 GHz WLAN Application
}

\author{
Jaswinder Kaur ${ }^{*}$, Rajesh Khanna \\ Department of Electronics and Communication Engineering, Thapar University, Patiala-147002, Punjab, India \\ *Corresponding author: jaswinder.kaur@thapar.edu
}

Copyright (C) 2013 Horizon Research Publishing All rights reserved.

\begin{abstract}
In this paper, the design of a co-axial fed single layer microstrip patch antenna (MSA) for $5.2 \mathrm{GHz}$ WLAN application is presented. The impedance matching and the radiation characteristics of this proposed structure are studied and analyzed using Computer Simulation Technology (CST) Microwave Studio, which is a commercially available electromagnetic simulator based on the method of finite difference time domain technique to achieve the desired specification. The proposed antenna based on co-axial feed configuration has the maximum achievable bandwidth obtained about 219.2 MHz (5.14-5.36 $\mathrm{GHz})$ at $-10 \mathrm{~dB}$ reflection coefficient which corresponds to WLAN $5.2 \mathrm{GHz}$ frequency band and the maximum achievable gain is $5.208 \mathrm{~dB}$. Stable radiation characteristics are obtained across the frequency band.
\end{abstract}

Keywords WLAN, Impedance Bandwidth, Co-Axial Fed, Microstrip Patch Antenna (MSA), CST Microwave Studio

\section{Introduction}

The growth of wireless systems and booming demand for a variety of new wireless applications such as WLAN (Wireless Local Area Network), it is important to design broadband and high gain antennas to cover a wide frequency range. The design of an efficient wide band small size antenna, for recent wireless applications, is a major challenge. In applications like high performance aircraft, satellite, missile, mobile radio and wireless communications small size, low-cost fabrication, low profile, conformability and ease of installation and integration with feed networks are the main constraints. Also, with advancement of the technology, the requirement of an antenna to resonate at more than one frequency i.e. multi-banding is also increasing day by day. Here microstrip patch antenna is the best choice to fulfill all the above requirements. Along with that a microstrip patch antenna offers many advantages above other conventional antennas like low fabrication cost, supports both, linear as well as circular polarization etc. Microstrip patch antenna have some disadvantages also like surface wave excitation, narrow bandwidth etc. But bandwidth of a microstrip patch antenna can be improved by various methods like cutting U-slot [1], increasing the substrate height, decreasing $\varepsilon_{r}$ of substrate etc. Antenna array can also be used to improve the bandwidth [2].

Here, to start with, a simple microstrip patch antenna with coaxial feed is designed [3-4]. In this feeding technique, the inner conductor of the coaxial connector extends from ground through the substrate and is soldered to the radiating patch, while the outer conductor extends from ground up to substrate. The main advantage of this type of feeding scheme is that the feed can be placed at any desired location inside the patch in order to properly match with its input impedance. This feed method is easy to fabricate and has low spurious radiation. However, its major drawback is that it provides narrow bandwidth and is difficult to model since a hole has to be drilled in the substrate and the connector protrudes outside the ground plane, thus not making it completely planar for thick substrates. But the bandwidth can be improved by various methods written above. Recently many microstrip patch antenna for different applications with coaxial-feed have been presented [5-8]. Figure 1 shows the co-axial feeding technique. Further, the details of the proposed design performance are presented and discussed.

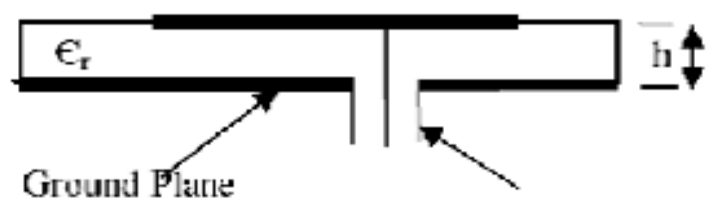

Coaxial Feed

Figure 1. Co-axial feeding technique

\section{Antenna Design}

Figure 2 shows the geometry of proposed coaxial fed microstrip patch antenna with single band operation for WLAN application. The antenna is excited by coaxial feed 
line designed for a $50 \mathrm{ohm}$ characteristic impedance and is printed on substrate with a thickness of $1.5748 \mathrm{~mm}$, dielectric constant of 2.5 and loss tangent of 0.0009 . The dimensions of the proposed antenna are written below:

Ground size $=27 \mathrm{~mm} \times 31 \mathrm{~mm}$

Substrate size $=27 \mathrm{~mm} \times 31 \mathrm{~mm}$

Patch size $=16 \mathrm{~mm} \times 21 \mathrm{~mm}$

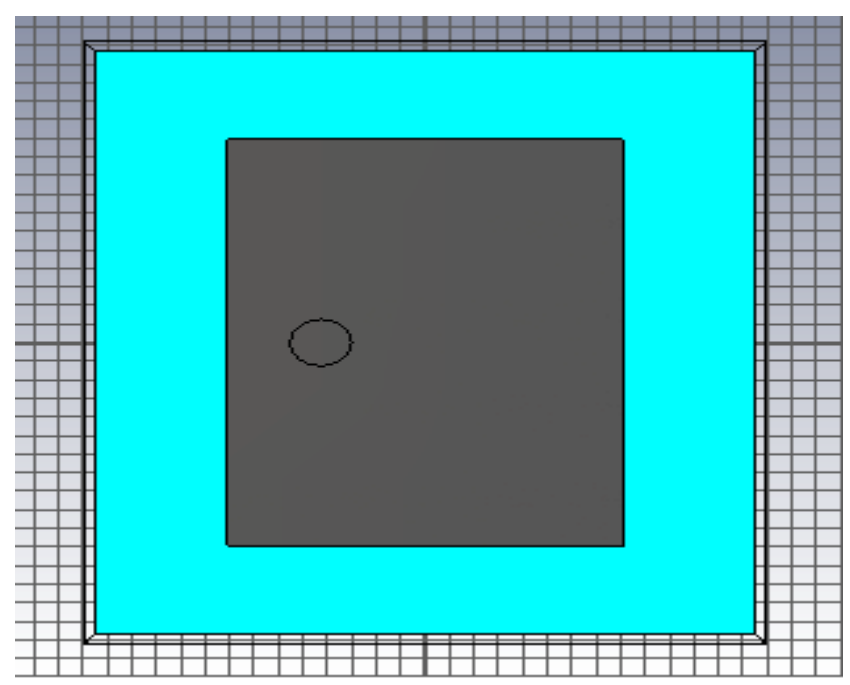

Figure 2. Front view of proposed microstrip patch antenna

The height of the ground which is beneath the substrate and made of PEC material is taken to be three times the thickness of substrate for simulation purposes i.e. $3 \times 1.5748 \mathrm{~mm}$ and of the patch which is also made of material PEC (Perfect Electric Conductor) is $0.02 \mathrm{~mm}$. The proposed antenna is fed by coaxial cable with a characteristic impedance of $50 \mathrm{ohm}$. So, the outer conductor (from bottom of ground to top of ground) is made of substrate material and inner conductor (from bottom of ground to top of patch) is made of PEC material. The inner and outer radius of co-axial probe is $1.25 \mathrm{~mm}$ and $4.6 \mathrm{~mm}$ respectively. The feed point for the proposed antenna is found to be $(-4.25,0)$ where the best impedance matching of $49.5 \mathrm{ohm}$ has been achieved which is very much close to $50 \mathrm{ohm}$. This has been done by applying parametric sweep for locating the feed point in the full range of $\mathrm{x}$-axis in the window of transient solver. Proper impedance matching always yields the best desired result.

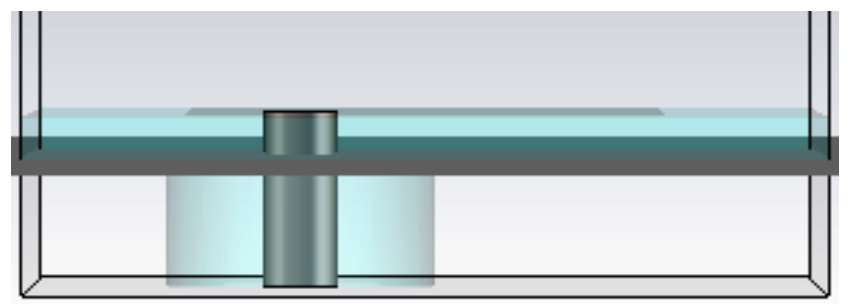

Figure 3. Bottom view of the proposed microstrip patch antenna

As the proposed antenna is coaxial fed so, we can view outer and inner conductor of the coaxial feed line very clearly in the above diagram.

\section{Simulation Results}

Simulation studies of proposed antenna reported here are carried out using CST Microwave Studio. Figure 4 shows the simulated reflection coefficient $\left[S_{11}\right]$ of the proposed antenna in dB. $S_{11}$ gives the reflection coefficient at port 1 where we apply the input to the microstrip patch antenna. It should be less than $-10 \mathrm{~dB}$ for the acceptable operation. It shows that the proposed antenna resonates at frequency equal to $5.244 \mathrm{GHz}$ which gives the measure of the wideband characteristic of the patch antenna. The simulated impedance bandwidth of about $219.2 \mathrm{MHz}(5.14-5.36 \mathrm{GHz})$ is achieved at $-10 \mathrm{~dB}$ reflection coefficient (VSWR $\leq 2)$. The reflection coefficient value that is achieved at this resonant frequency is equal to $-23.901 \mathrm{~dB}$. This reflection coefficient value suggests that there is good matching at the frequency point below the $-10 \mathrm{~dB}$ region. It covers the frequency band for the WLAN application i.e. $5.15-5.35 \mathrm{GHz}$.

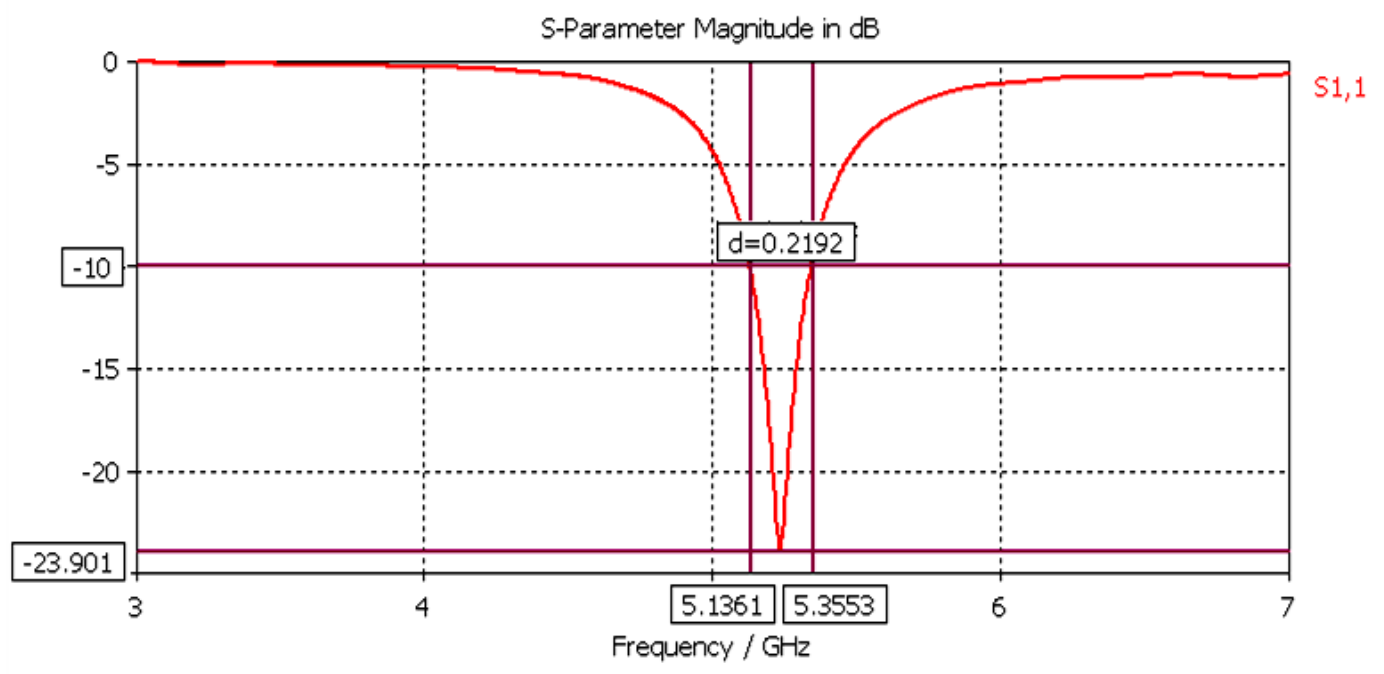

Figure 4. Simulated reflection coefficient [S11] of the proposed microstrip patch antenna 
Figure 5 shows the smith chart of the proposed antenna. It is a graphical representation of the normalized characteristic impedance. The Smith chart is one of the most useful graphical tools for high frequency circuit applications. The goal of the Smith chart is to identify all possible impedances on the domain of existence of the reflection coefficient.

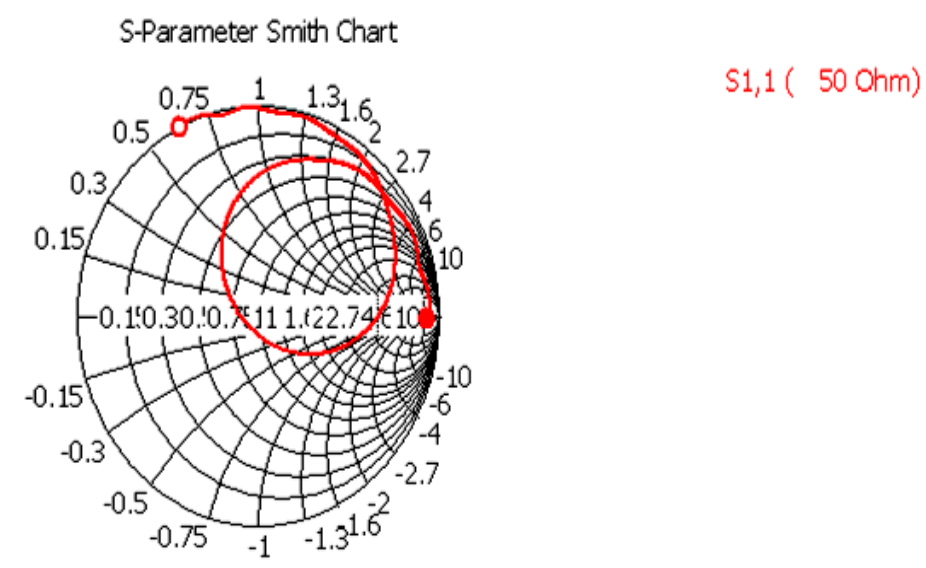

Figure 5. Smith chart of the proposed microstrip patch antenna

Radiation pattern is a graphical depiction of the relative field strength transmitted from or received by the antenna. The antenna should not have the side lobes and back lobes ideally. We cannot remove them completely but we can minimize them. Figure 6 shows the simulated 3-D radiation pattern with directivity of $5.391 \mathrm{dBi}$ for proposed antenna configuration at the resonating frequency of $5.244 \mathrm{GHz}$.

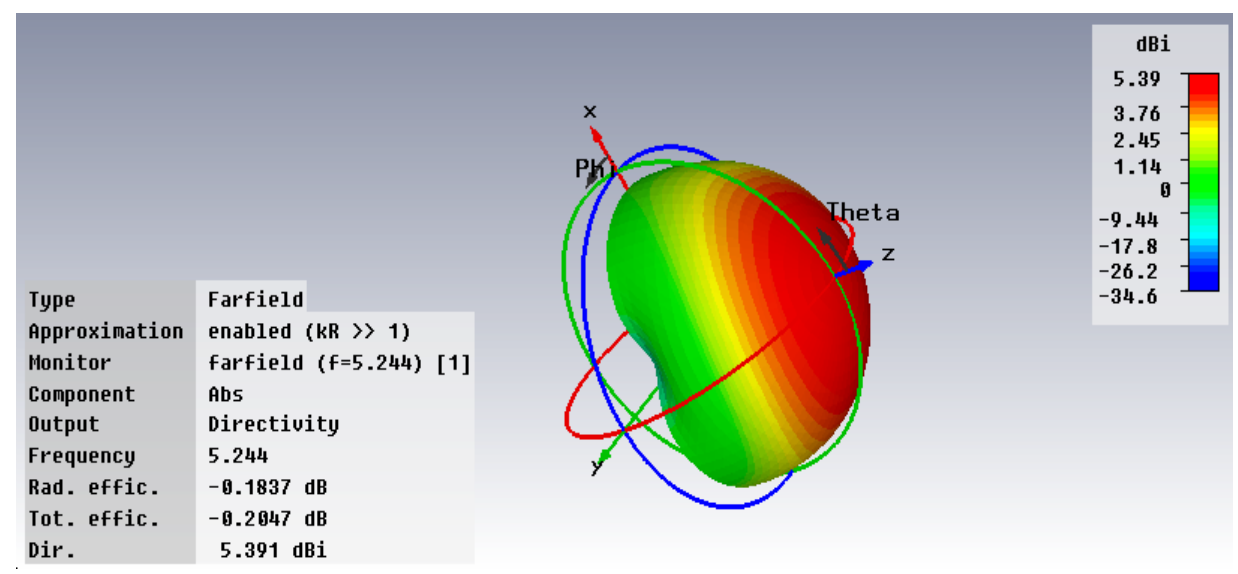

Figure 6. 3D Radiation pattern for $f_{r}=5.244 \mathrm{GHz}$

Figure $7(\mathrm{a})$ and (b) show the simulated E-plane (phi $=90^{\circ}$, theta $=$ varying) and H-plane (theta $=90^{\circ}$, phi=varying) radiation patterns for proposed antenna configuration at the resonating frequency of $5.244 \mathrm{GHz}$.

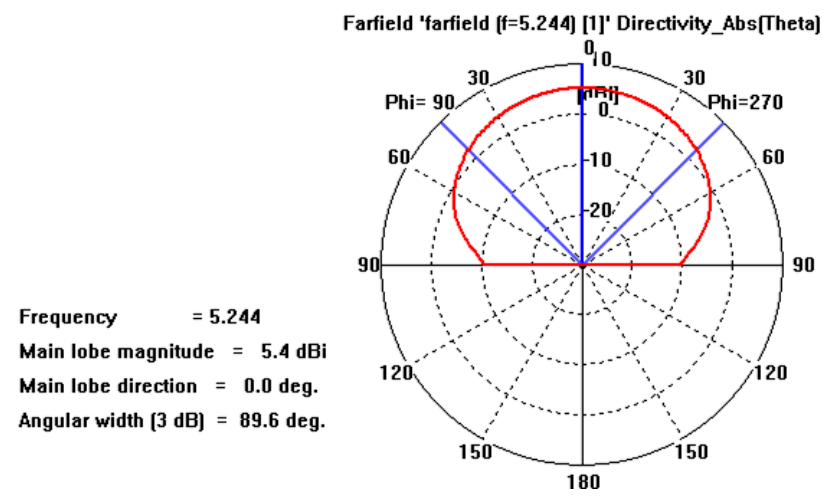

(a)

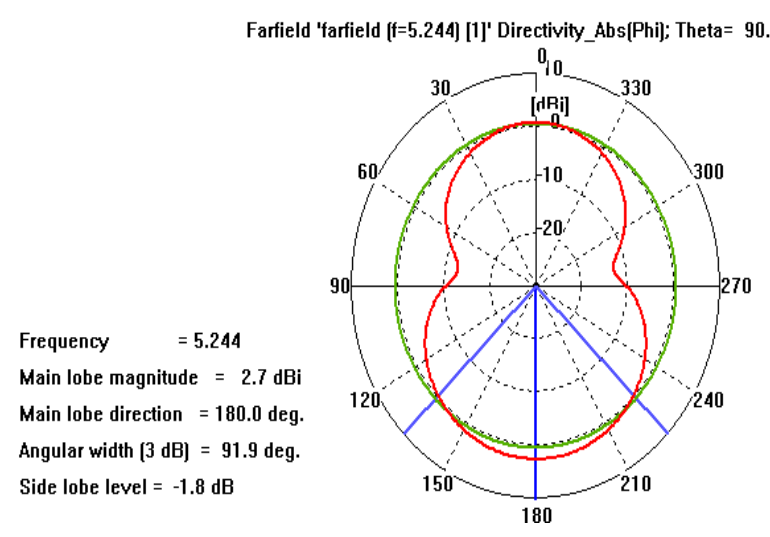

(b)

Figure 7. (a) E-plane radiation pattern for $f_{r}=5.244 \mathrm{GHz}$ (b) H-plane radiation pattern for $f_{r}=5.244 \mathrm{GHz}$ 
Figure 8 shows the VSWR (voltage standing wave ratio) plot for the designed antenna. The value of VSWR should lie between 1 and 2. SWR is used as an efficiency measure for transmission lines, electrical cables that conduct radio frequency signals, used for purposes such as connecting radio transmitters and receivers with their antennas, and distributing cable television signals. Here the value of the VSWR for the proposed microstrip patch antenna is 1.15 at the specified resonating frequency. The achieved values of reflection coefficient and VSWR are small enough and frequency is closed enough to specified frequencies bands for 5.2 GHz WLAN application. The maximum achievable gain is $5.208 \mathrm{~dB}$ at the resonating frequency of $5.244 \mathrm{GHz}$.

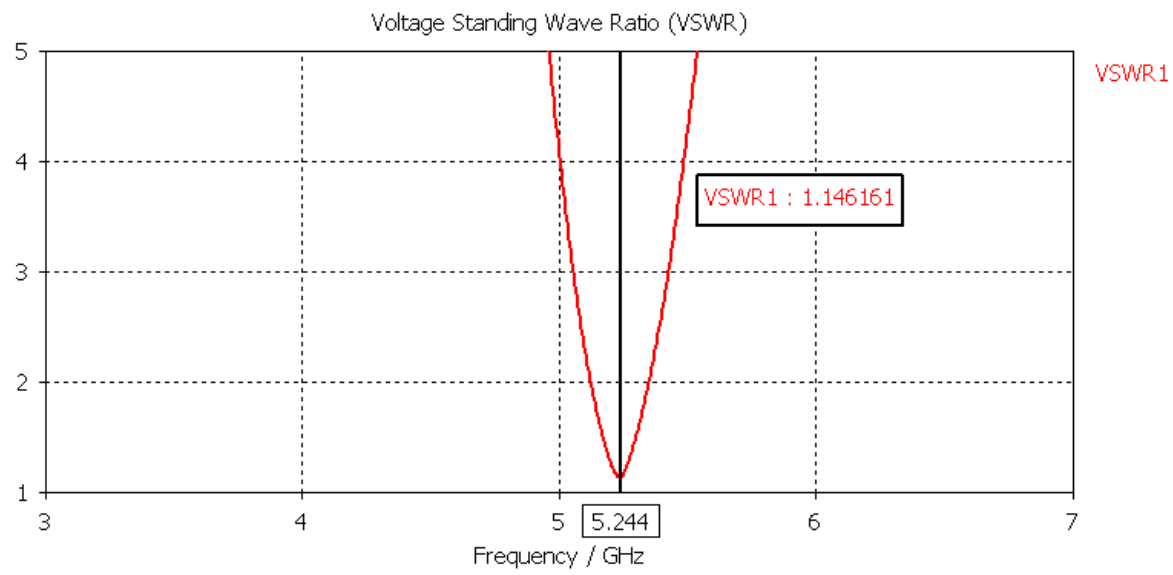

Figure 8. VSWR plot for the proposed microstrip patch antenna

Figure 9 shows the surface current distribution for the resonating frequency of $5.244 \mathrm{GHz}$. The dimensions of patch are completely responsible for the radiation and making the design feasible for an application in $5.2 \mathrm{GHz}$ WLAN standard. The feed point is located such that an excellent impedance matching of approximately $50 \mathrm{ohm}$ is obtained.

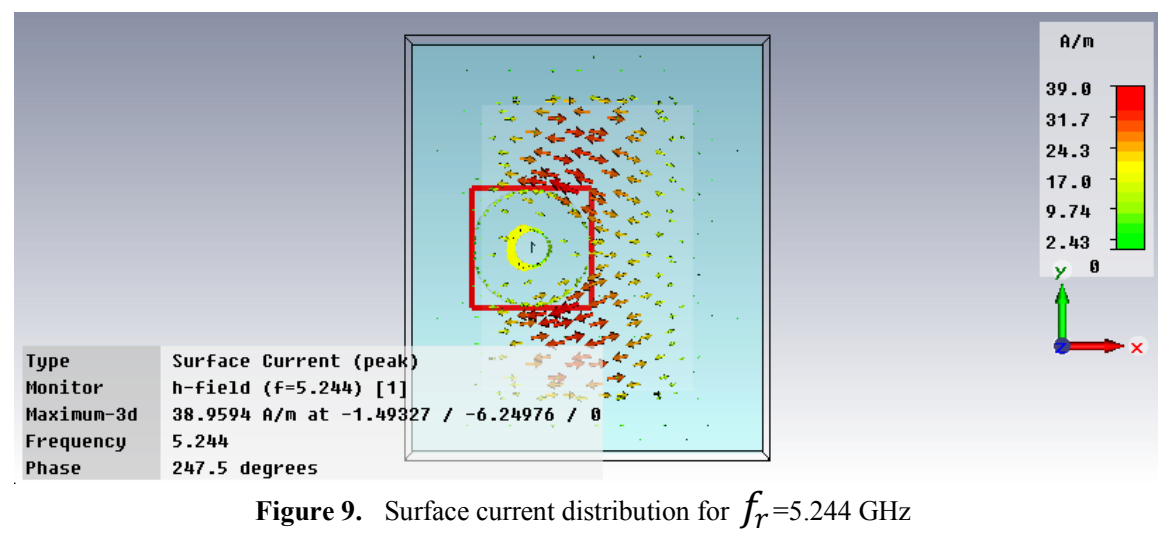

\section{Discussion}

In this study, a simple coaxial fed microstrip patch antenna for application in $5.2 \mathrm{GHz}$ WLAN frequency band has been demonstrated and implemented using CST Microwave Studio software. The proposed antenna is designed to operate at $5.244 \mathrm{GHz}$ WLAN frequency band which corresponds to IEEE $802.11 \mathrm{a}(5.15-5.35 \mathrm{GHz})$ WLAN application. It can be observed that the achievable impedance bandwidth of $219.2 \mathrm{MHz}$ at the resonating frequency of $5.244 \mathrm{GHz}$ is obtained due to proper impedance matching at the optimized feed point on the design. The reflection coefficient achieved at the resonant frequency is equal to $-23.901 \mathrm{~dB}$. Hence it covers the WLAN band (5.15-5.35) GHz.

It can be noticed that acceptable broadside radiation pattern is obtained at the resonating frequency of $5.244 \mathrm{GHz}$.
In this proposed design a gain of $5.208 \mathrm{~dB}$ has been investigated for the frequency of $5.244 \mathrm{GHz}$. The value of gain is not good enough for an acceptable operation. We can further analyze this designed structure by cutting different slots on the patch. We can also see the impact of slots on the different antenna parameters in future.

\section{Conclusion}

In this study, a simple coaxial fed microstrip patch antenna for application in $5.2 \mathrm{GHz}$ WLAN frequency band has been demonstrated and implemented using CST Microwave Studio software. The proposed antenna exhibits a bandwidth of about $219.2(5.14-5.36 \mathrm{GHz})$ at $-10 \mathrm{~dB}$ reflection coefficient which corresponds to $5.2 \mathrm{GHz}$ WLAN standard. The maximum achievable gain is $5.208 \mathrm{~dB}$ with the 
corresponding reflection coefficient of $-23.901 \mathrm{~dB}$. The proper impedance matching of the proposed antenna is achieved by adjusting the coaxial feeding structure. In addition, the proposed antenna shows a well defined stable radiation pattern over the band which makes the design suitable for wireless communication applications. Although this antenna was designed for WLAN band application, the design concept can be extended to other frequency bands of interest by cutting various slots on the patch or in the ground, thus making the ground a defected ground structure. Work is going on to get even better results with increased gain and bandwidth and making this design covering other WLAN bands also by making this structure a multiband one. Also, due to the lack of fabrication facilities at our institute, this design is still not fabricated which is a gap for this paper and also a next aim for us.

\section{Acknowledgements}

The authors are thankful to Dr. M.V. Kartikeyan, Millimeter Wave Laboratory, I.I.T, Roorkee, India, for providing necessary guidance and valuable comments while writing the research paper. Thanks are also due to $\mathrm{Mr}$. J. Malik for his help and cooperation.

\section{REFERENCES}

[1] M. Mahmoud, "Improving the Bandwidth of U-slot Microstrip Antenna Using a New Technique (Trough-Slot Patch)" Region 5 IEEE Conference.

[2] A. B. Smolders, "Broadband microstrip array antennas" Antennas and Propagation Society International Symposium, 1994.

[3] R. Garg, P. Bhartia, I. Bahl and A.I tipiboon, "Microstrip antenna design handbook", Artech House, Boston - London, 2000 .

[4] C. A. Balanis, "Antenna Theory Analysis and Design", Third Edition, Wiley, New Jersey, 2005.

[5] Jun-Hai Cui, Shun-Shi Zhong, "Compact microstrip patch antenna with C-shaped slot" Microwave Conference, Asia-Pacific, 2000.

[6] N. A. Murad, M. Esa and S. Tukachil, "Microstrip U-Shaped Dual-Band Antenna" Asia-Pacific conference on Applied Electromagnetics Proceedings, 2005.

[7] K. Kumar and N. Gunasekaran, "A Novel Wide Band Planar n Shaped Base Station Antenna", International Conference on Communications and Signal Processing (ICCSP), 2011.

[8] J. Kaur, R. Khanna and M. Kartikeyan, "Design of co-axial fed broadband single layer rectangular microstrp patch antenna for wireless applications" J. Engg. Technol., Vol. 3, No. 2, pp. 71-75, 2013. 